\title{
Daniel Fridman, El sueño de vivir sin trabajar. Una sociología del emprendedorismo, la autoayuda financiera y el nuevo individuo del siglo XXI, Buenos Aires, Siglo XXI, 2019, 239 pp.
}

Reseña por Gonzalo Aguirre Orellana*

Licencia Creative Commons Atribución-NoComercial (CC BY-NC) 4.0 Internacional

Perfiles Latinoamericanos, 28(56) | 2020 | e-ISSN: 2309-4982 DOI: http://doi.org/10.18504/pl2855-018-2020

E

libro de Daniel Fridman, académico de la Universidad de Texas, fue publicado originalmente en inglés en 2016. La obra obtuvo una mención honrosa en el concurso al mejor libro de 2016-2017 de la Asociación de Sociología Americana, en la categoría de Consumidores y Consumo. La reedición en español de este libro, publicada en 2019, traduce a nuestro idioma una etnografía que interroga aspectos fundamentales de las formas de vida y de gobernanza que actualmente caracterizan a Latinoamérica. Fridman intenta describir un submundo muy particular, pero que puede decir mucho sobre la forma en que el neoliberalismo adquiere materialidad "desde abajo", al nivel de las aspiraciones personales y las prácticas cotidianas.

Fridman estudia las redes de consumidores de "autoayuda financiera”. Este género literario, cuyo mayor representante es el "gurú de las finanzas" Robert Kiyosaki, busca entregar herramientas para que sus lectores puedan transformarse a sí mismos y alcanzar un ideal de trascendencia, que si bien depende en gran medida del éxito en el ámbito económico, no se limita a ello. Para los consumidores de los libros de Kiyosaki, el dinero es un medio para un fin mayor: la libertad financiera o la utopía de vivir sin trabajar. Los sujetos estudiados por Fridman tienen distintos orígenes y profesiones, pero coinciden en desear la movilidad social asociada a la obtención de flujos de dinero (mediante inversiones en la bolsa, compra de bienes raíces, mercadeo en red), que les permitan percibir ingresos suficientes para cubrir sus necesidades, evadiendo permanen-

* Magíster en Sociología por la Universidad Alberto Hurtado (Chile). Tesista proyecto Anillos Conicyt SOC180039 | gaaguirre@uc.cl 
temente la obligación de trabajar para subsistir. Los consumidores ingresan al mundo de la autoayuda financiera a través del libro de Kiyosaki. Sin embargo, encuentran un espacio para el desarrollo y la expresión de sus aspiraciones personales en la participación en organizaciones de individuos con intereses similares. Fridman estudia redes de autoayuda financiera de dos ciudades diferentes, Nueva York y Buenos Aires, poniendo atención a las semejanzas y diferencias en la adopción de las enseñanzas de Kiyosaki en cada contexto. La etnografía lleva al lector por espacios físicos y digitales, y por la obra de Kiyosaki y los sueños $\mathrm{y}$ aspiraciones de quienes la consumen.

Para dar cuenta de este fenómeno, Fridman toma principalmente dos teorías: las tecnologías del yo, de Michel Foucault, y la performatividad económica, de Michel Callon. En conjunto, ambas perspectivas le permiten observar cómo la autoayuda financiera promueve la emergencia de un sujeto neoliberal, autogobernado y responsable de sí mismo. En síntesis, Fridman caracteriza la autoayuda financiera en tres ejes. El primero es un componente técnico, consistente en la internalización de conocimientos de cálculo y contabilidad. Mediante la "educación financiera", los sujetos aprenden a moverse en el mundo de las finanzas y a gobernarse a sí mismos. El segundo es un componente emocional, orientado a la transformación del yo, especialmente enfocado en perder el miedo a tomar riesgos en el ámbito económico y el cambio en la mentalidad respecto al dinero en general. Por último, Fridman identifica un componente sociológico, una idea clara sobre el funcionamiento de la sociedad y las dinámicas de las clases sociales. Este último eje es lo que diferencia a la autoayuda financiera de géneros literarios y prácticas semejantes. Para los seguidores de Kiyosaki, la sociedad tiene dos clases antagónicas: los ricos y los pobres. La diferencia entre ambas no radica únicamente en la posesión de medios de producción, sino en la libertad individual. De este modo, la movilidad social no depende de la riqueza acumulada, el nivel educativo o la ocupación, sino de un sentido trascendente de independencia respecto a cualquier institución social o necesidad personal.

Los tres primeros capítulos del libro son más bien descriptivos y ubican al lector en el mundo de la autoayuda financiera, caracterizando este género literario, la obra de Robert Kiyosaki y las dinámicas internas de los grupos de consumidores. En el capítulo 1, el autor explica los fundamentos de la autoayuda financiera, el contexto en que emerge y la teoría de las clases sociales en que se sustenta. Para quienes participan en este mundo, las enseñanzas de Kiyosaki permiten desprenderse de lógicas propias de una sociedad industrial — por ejemplo, la educación como medio de movilidad social—, y adquirir las habilidades necesarias para alcanzar el éxito en la "sociedad de la información" actual. En el capítulo 2, Fridman caracteriza el ideal fundamental de la autoayuda financiera: la libertad. En la perspectiva de los sujetos estudiados, tanto 
un gerente millonario como un empleado de bajos ingresos son iguales, ya que ambos dependen de un salario para vivir. La libertad anhelada es la independencia total en relación con toda institución —el Estado, la seguridad social, la familia, la empresa—y respecto a toda constricción interna — el miedo a invertir y las lógicas tradicionales de acción-. En este sentido, es posible interpretar en la obra de Fridman una reflexión sobre la modernidad, tema clásico en la sociología, dado que se infiere la existencia de individuos más individualizados y una sociedad más compleja. No obstante, la obra se centra mayormente en la perspectiva de los sujetos, dejando un poco de lado la reflexión sobre las condiciones estructurales de cada contexto, encerrando esta interrogante en la caja negra del neoliberalismo.

El foco del capítulo 3 es un juego de mesa creado por Robert Kiyosaki. Además de obtener herramientas técnicas y de superación personal, quienes asisten a clubes de autoayuda financiera participan en un juego llamado "Cashflow". Este juego comprende un tablero, en el que los jugadores son representados por ratas. Con el lanzamiento de dados, los jugadores mueven sus piezas en un circuito cerrado, ganando y perdiendo dinero, hasta juntar capital suficiente para salir de la "carrera de la rata" y perseguir sus sueños en una segunda sección, la "vía rápida". Este juego tiene tres funciones: primero, es una instancia para que los jugadores se reúnan y formen redes. Segundo, tiene una finalidad pedagógica. El juego pretende que los participantes internalicen una racionalidad particular. Utilizando una planilla de ingresos y egresos, los jugadores desarrollan habilidades de cálculo, con el fin de modificarse a sí mismos y desarrollar la "inteligencia financiera" en la vida real. Por último, el juego permite que los participantes simulen la posición de inversores exitosos. Aunque el libro logra rescatar la perspectiva de los "sujetos neoliberales", a ratos se centra exageradamente en la figura de Robert Kiyosaki y su obra, perdiendo de foco el objeto etnográfico que pretende seguir.

El capítulo 4 es más analítico que los anteriores. Si bien la autoayuda financiera tiene una orientación individualista, no promueve una lógica plenamente individual. Quienes participan en los grupos estudiados por Fridman son continuamente estimulados a generar redes y trabajar en conjunto. El autor problematiza la tensión entre acciones interesadas y acciones desinteresadas en las prácticas de los participantes de la autoayuda financiera. Comúnmente, ambas orientaciones son vistas como excluyentes, de tal modo que el interés subyacente hace menos auténtica una acción generosa. Sin embargo, para los miembros de los clubes estudiados, no hay tal contradicción. Todos los participantes exponen abiertamente su interés económico, a la vez que portan una ética de desarrollo personal y colectivo. En este sentido, una de las reflexiones transversales a la obra de Fridman es que, para los sujetos estudiados, la búsqueda de 
una comunidad de pares, donde se sientan comprendidos y apoyados, puede ser más relevante que una orientación puramente económica.

En el capítulo 5 Fridman se propone analizar las particularidades de la apropiación de la autoayuda financiera en Argentina. Al tratarse de un conocimiento formulado específicamente para el contexto estadounidense, no hace sentido inmediatamente a los lectores argentinos. Hay un neoliberalismo global, que permite cierto nivel de entendimiento de los conceptos elaborados por Kiyosaki. Sin embargo, por la gran diferencia en la dinámica interna de ambas economías, muchas cosas simplemente no son representativas de la realidad de Argentina. Fridman señala que, dada la historia de crisis económicas de este país, la mayor parte de la población desconfía de las instituciones financieras, lo que afecta negativamente la capacidad de inversión individual y la toma de riesgos financieros. Los lectores de autoayuda financiera deben traducir, con bastante esfuerzo, los conceptos de Kiyosaki para que encajen con las particularidades de los contextos locales. En este sentido, la globalización descrita por Fridman depende en gran medida de la capacidad de adaptación y la creatividad de los usuarios.

En las conclusiones, Fridman resume los argumentos centrales del libro y aleja el foco de los sujetos estudiados, para extender el análisis hacia la "financiarización" del mundo y el avance del neoliberalismo. Para Fridman, lo narrado a lo largo del libro puede ayudar a interpretar otras iniciativas, tanto públicas como privadas, que promueven una racionalidad neoliberal y la alfabetización financiera de la población. Es por ello que destaca la figura del emprendedor como el sujeto legítimo del neoliberalismo y la promoción del emprendimiento como una forma de superar la pobreza y alcanzar el desarrollo.

Al final del libro, el autor incluye un anexo metodológico sobre su posicionamiento etnográfico. Este material enriquece considerablemente esta obra, dado que da cuenta reflexivamente de su proceso de producción. En este último apartado Fridman hace explícitas sus decisiones, tanto en términos de la producción de datos como en el proceso de escritura. La estrategia descriptiva de Fridman es realista. Busca alejarse de los sujetos de estudio, es decir, abstraerse de la narración, para presentar de mejor forma las interacciones que observa. El único comentario que tengo sobre la técnica elegida es que en este juego de cercanía y distancia la voz del autor a ratos se funde con la de los seguidores de Kiyosaki, perdiendo parte de su perspectiva crítica.

A modo de cierre, considero que la etnografía de Fridman logra representar un fragmento poco visible de las formas de vida del neoliberalismo contemporáneo, probando que estudiar estos espacios es significativo. Desde una posición cercana en lo metodológico y distante en lo analítico, el autor da cuenta de los detalles de un mundo que a primera vista parece trivial, pero que, bajo 
esa superficie, moviliza discursos y tensiones fundamentales para comprender el mundo contemporáneo. Tal vez lo más relevante es que logra capturar expresiones locales del neoliberalismo global, remarcando que este fenómeno no emana desde estructuras distantes, sino que adquiere carne en los deseos y prácticas de sujetos concretos. Uno de los aportes de esta obra, en mi opinión, es que logra capturar los conceptos de los sujetos estudiados y mostrar su perspectiva particular del mundo, bajo el riesgo de oscurecer un poco la perspectiva del autor mismo.

La obra deja algunos puntos abiertos e interrogantes sin responder. El análisis etnográfico de Fridman, por la estrategia metodológica utilizada, se centra principalmente en las interacciones de los consumidores de autoayuda financiera en el contexto de sus clubes y organizaciones. Hace falta ver cómo estos aprendizajes son integrados en las vidas cotidianas de los participantes. Así, a lo largo de la obra queda claro que las orientaciones neoliberales no son una consecuencia de la participación en los clubes de autoayuda financiera, ni de otras formas de alfabetización financiera. Por el contrario, los actores portan previamente una forma de pensar y de actuar, que encuentra un modo de expresión en los espacios creados por las comunidades que siguen a Kiyosaki. En este punto podríamos preguntar, ¿qué es aquello que preexiste en los sujetos? ¿Cómo se formaron esas orientaciones neoliberales? El enfoque del libro en los sujetos y la autoayuda financiera podría complementarse con dos análisis adicionales: por una parte, sobre las trayectorias biográficas — cómo estas prácticas se insertan en sus vidas, cómo afectan cada trayectoria particular-; por otra, sobre las condiciones estructurales que caracterizan estas trayectorias y cómo se entrelazan con las orientaciones individuales. 
